\title{
Derivational networks in Welsh
}

\section{Nurmio, Silva Mikaela}

de Gruyter

2020-05-18

Nurmio , S M 2020 , Derivational networks in Welsh . in L Körtvélyessy , A Bagasheva \& P pÿ tekauer (eds), Derivational Networks Across Languages . Trends in Linguistics. Studies and Monographs [TiLSM] , vol. 340 , de Gruyter , Berlin , pp. 309-318 . https://doi.org/10.1515/9783110686630-031

http://hdl.handle.net/10138/318012

https://doi.org/10.1515/9783110686630-031

unspecified

acceptedVersion

Downloaded from Helda, University of Helsinki institutional repository.

This is an electronic reprint of the original article.

This reprint may differ from the original in pagination and typographic detail.

Please cite the original version. 
Pre-publication version

For the definitive version, see https://doi.org/10.1515/9783110686630-031

\section{Derivational networks in Welsh}

\section{Silva Nurmio}

\section{General notes}

Affixation is a major way of deriving new words in Welsh. For detailed discussion of different affixes, see Russell (1990) and Zimmer (2000). Compounding is another main strategy, for which see Zimmer (2000) and Russell (2015b). Welsh affixes include many which were abstracted from Latin borrowings, such as the adjectival suffix -us (e.g. deallus 'intelligent', cf. deall- 'to understand') from the Latin suffix -ōsus (Russell 2015b: 2774).

There are two kinds of Welsh words which pose a problem for a clear split into inflection and derivation: verbal nouns (from verbal bases) and singulatives. 'Verbal noun' or 'verb noun' (W berfenw) is a traditional term for non-finite forms in the Celtic languages (which roughly correspond to participles, infinitives and also deverbal nouns in languages like English); see the general introduction to the Celtic languages for more discussion. Unlike verbal nouns from verbal bases, verbal nouns formed from nouns and adjectives were included in this study, since these clearly involve adding a suffix to derive a new word, e.g. llygad- $u$ 'to eye (verbal noun)' from llygad 'eye' (noun).1

Welsh has two singulative-forming suffixes: - yn (masc.) and -en (fem.), e.g. moch 'pigs', mochyn 'a pig' (see Nurmio 2017 and references there). With bases which are count plurals (called 'morphological collectives' by Nurmio 2017), like moch, the singulative suffixes can be argued to form inflectional singular/plural pairs. These suffixes also attach to mass and non-nominal bases, however, e.g. ceirch 'oats', ceirchen 'a grain of oats', and in such cases the addition of the singulative suffix is closer to derivation. The sample nouns included one morphological collective, llau 'lice', singulative lleuen 'louse'. Here the collective is the base for derivation, and the singulative was not included as a derivative, since it was treated as an inflectional form. The suffixes $-y n /-e n$ also function as diminutive suffixes when added to singular count noun bases. Such derivatives were included in this study, e.g. caregyn 'a small stone, pebble' (from carreg 'stone').

\footnotetext{
1 The reason that such verbal nouns were not analysed as derived from verbal stems (e.e. llygad 'eye (noun)' $>$ llygad- 'to eye' (verbal stem) > llygad-u (verbal noun)) is that the verbal noun is much more common in use than inflected forms, which supports an analysis that the verbal noun is derived directly from the noun or adjective. This view also seems to be taken by Borsley et al. (2007: 68).
} 
Pre-publication version

For the definitive version, see https://doi.org/10.1515/9783110686630-031

Another theoretical problem is the occasional use of the plural as a stem for adding affixes. In the sample for this study, this may be the case with e.g. llygeidiog 'having eyes, having large eyes'. It is not fully clear whether the base is the plural llygaid 'eyes', or the singular llygad 'eye' with vowel raising regularly caused by the suffix -iog (see Russell 2015b: 2774, Russell 1990: 39-60). Llygeidiog occurs alongside its synonym llygadog based on the singular, and the two were counted as one entry for the purposes of this study, taking the former tentatively as a vowel alternation variant. However, the privative dilygaid 'eyeless' must have the plural as its base, and this form was excluded from the derivational network of 'eye'. The noun dant 'tooth' also has a different stem danhedd- used for some derivatives, e.g. danheddog 'having teeth'. Russell (1990: 118-119) has shown that this stem is in origin the oblique stem of this noun, reflecting a preservation of an archaic Brittonic pattern where the oblique stem, not the nominative, was used in word-formation. Although diachronically danhedd-is not the plural, it is likely to be understood as such synchronically, and such derivatives were therefore excluded from the derivational network of dant 'tooth'.

The common agent and instrument suffixes -wr (masc.) and -wraig (fem.), e.g. torr$w r$ 'cutter (person or implement)', from gîwr 'man' and gwraig 'woman' with an initial consonant mutation that deletes $/ \mathrm{g}-/$, are treated here as affixoids and therefore excluded from the derivational networks (see Russell 1989: 34-36 and 1996: 121, 125 for further discussion). For other possible affixoids, see Russell (2015b: 2772), and for other agent suffixes, see Zimmer (2000: 551-554).

Welsh has a suffix -edig which historically formed past participles from verbal bases, e.g. toredig 'broken, cut' from torr- 'to cut' (see Russell 1995: 258-259, Russell 1990: 7879). Synchronically, however, such derivatives are used as adjectives and they do not feature in verbal constructions. The standard grammar by Thomas (2006: 675-676) lists -edig as an adjectival suffix, reflecting how it is viewed synchronically (see also Borsley et al. 2007: 69).2 For perfect aspect ('has done X'), Modern Welsh uses the construction wedi + verbal noun (the aspectual marker wedi is grammaticalised from the preposition wedi 'after'), e.g.

\footnotetext{
${ }^{2}$ I have included -edig derivatives here, arguing that they should be regarded as adjectives synchronically, and not adjectives formed by conversion from a verbal form, even though this may be the case historically. The verbal connection is still apparent in the fact that intransitives often lack an -edig derivative, or it is only marginally attested (the present study only includes transitive verbs, however). The same argument applies to derivatives with the suffix -adwy, e.g. llosgadwy 'burnable' from llosg- 'to burn', which originally had a future participle or gerundive force (Evans 1964: 166) but which is now an adjective-forming suffix.
} 
Pre-publication version

For the definitive version, see https://doi.org/10.1515/9783110686630-031

mae hi wedi mynd

be.3SG.PRES.INDIC she PRT gO.VERBAL NOUN

'she has gone'

The sources used for creating the Welsh corpus are the Dictionary of the Welsh Language (Thomas et al. 1950-), the Welsh Academy Dictionary (Griffiths \& Jones 1997), the searchable corpora of the Welsh National Corpora Portal (http://corpws.cymru/) and the Welsh National Terminology Portal (http://termau.cymru). Native speaker judgements, and occasional Google searches, were used to verify derivatives the present-day usage of which was not clear from the corpora and dictionaries.

\section{Maximum derivational networks}

Table 1 shows the maximum derivational network for each word-class per order of derivation. Verbs have the largest derivational networks in all orders. Third- and fourth-order derivatives are rare, and only verbs and adjectives have some fourth order derivatives.

\begin{tabular}{|c|c|c|c|c|c|}
\hline & 1 st order & 2nd order & 3rd order & 4th order & $\sum$ \\
\hline Nouns & 35 & 15 & 1 & 0 & 51 \\
\hline Verbs & 38 & 31 & 12 & 3 & 84 \\
\hline Adjectives & 24 & 10 & 3 & 1 & 38 \\
\hline TOTAL & 97 & 56 & 16 & 4 & 173 \\
\hline
\end{tabular}

Table 1 Maximum derivational network per order of derivation for all three word-classes

\section{Saturation values}

Tables 2-4 record the saturation values for nouns, verbs and adjectives respectively, and Table 5 sums up the average saturation value for each word-class. There is much variation in saturation values between different lexemes: the highest value for nouns is $50.98 \%$ (enw 'name') while the lowest is $5.88 \%$ (llau 'lice (pl.)'). For verbs, the percentages are $66.67 \%$ (gwybod-/gwybydd- 'to know') and 1.19\% (rho(dd)- 'to give') and for adjectives $39.47 \%$ (newydd 'new') and 13.16\% (four adjectives have this percentage, see Table 4). The average saturation values in Table 5 are fairly low for all word-classes, generally staying below $20 \%$, apart from 1 st order derivatives of adjectives with the average of $27 \%$. 


\begin{tabular}{|c|c|c|c|c|}
\hline Nouns & $\begin{array}{l}\text { Saturation } \\
\text { value }(\%)\end{array}$ & $1_{\text {st }} \operatorname{order}(\%)$ & 2 nd $\operatorname{order}(\%)$ & 3rd order $(\%)$ \\
\hline asgwrn 'bone' & 13.73 & 17.14 & 6.67 & 0 \\
\hline llygad 'eye' & 9.80 & 14.29 & 0 & 0 \\
\hline dant 'tooth' & 15.69 & 17.14 & 13.33 & 0 \\
\hline$d y d d$ 'day' & 21.57 & 28.57 & 6.67 & 0 \\
\hline$c i$ 'dog' & 17.65 & 14.29 & 20 & 100 \\
\hline llau 'lice (pl.)' & 5.88 & 8.57 & 0 & 0 \\
\hline tân 'fire' & 13.73 & 17.14 & 6.67 & 0 \\
\hline carreg 'stone' & 17.65 & 17.14 & 20 & 0 \\
\hline$d \hat{w} r$ 'water' & 19.61 & 28.57 & 0 & 0 \\
\hline enw 'name' & 50.98 & 37.14 & 86.67 & 0 \\
\hline
\end{tabular}

Table 2 Saturation values per order of derivation for nouns

\begin{tabular}{|l|l|l|l|l|l|}
\hline \multicolumn{1}{|c|}{ Verbs } & \multicolumn{1}{|c|}{$\begin{array}{c}\text { Saturation } \\
\text { value (\%) }\end{array}$} & \multicolumn{1}{|c|}{$\begin{array}{c}\text { 1st } \\
\text { order }(\%)\end{array}$} & $\begin{array}{c}\text { 2nd } \\
\text { order } \\
(\%)\end{array}$ & $\begin{array}{c}\text { 3rd } \\
\text { order } \\
(\%)\end{array}$ & $\begin{array}{c}\text { 4th } \\
\text { order } \\
(\%)\end{array}$ \\
\hline torr- 'cut' & 11.9 & 23.68 & 3.23 & 0 & 0 \\
\hline clodd- 'dig' & 8.33 & 15.79 & 3.23 & 0 & 0 \\
\hline tynn- 'pull' & 17.86 & 23.68 & 6.45 & 25 & 33.33 \\
\hline tafl- 'throw' & 8.33 & 18.42 & 0 & 0 & 0 \\
\hline rho(dd)- 'give' & 1.19 & 2.63 & 0 & 0 & 0 \\
\hline dal(i)- 'hold' & 9.52 & 13.16 & 9.68 & 0 & 0 \\
\hline gwn- 'sew' & 3.57 & 7.89 & 0 & 0 & 0 \\
\hline llosg- 'burn' & 22.62 & 23.68 & 32.26 & 0 & 0 \\
\hline yf- 'drink' & 3.57 & 5.26 & 3.23 & 0 & 0 \\
\hline gwybod-/gwybydd- 'know' & 66.67 & 42.11 & 83.87 & 91.67 & 100 \\
\hline
\end{tabular}

Table 3 Saturation values per order of derivation for verbs

\begin{tabular}{|c|l|l|l|l|l|}
\hline \multicolumn{1}{|c|}{ Adjectives } & $\begin{array}{c}\text { Saturation } \\
\text { value (\%) }\end{array}$ & $\begin{array}{c}1 \text { st } \\
\text { order (\%) }\end{array}$ & $\begin{array}{c}\text { 2nd } \\
\text { order (\%) }\end{array}$ & $\begin{array}{c}\text { 3rd } \\
\text { order (\%) }\end{array}$ & $\begin{array}{c}\text { 4th } \\
\text { order (\%) }\end{array}$ \\
\hline cul 'narrow' & 13.16 & 20.83 & 0 & 0 & 0 \\
\hline
\end{tabular}




\begin{tabular}{|l|l|l|l|l|l|}
\hline hen 'old' & 34.21 & 33.33 & 50 & 0 & 0 \\
\hline syth 'straight' & 13.16 & 20.83 & 0 & 0 & 0 \\
\hline newydd 'new' & 39.47 & 25 & 50 & 100 & 100 \\
\hline hir 'long' & 13.16 & 20.83 & 0 & 0 & 0 \\
\hline cynnes 'warm' & 18.42 & 25 & 10 & 0 & 0 \\
\hline tew 'thick' & 28.95 & 29.17 & 40 & 0 & 0 \\
\hline drwg 'bad' & 23.68 & 33.33 & 10 & 0 & 0 \\
\hline tenau 'thin' & 26.32 & 41.67 & 0 & 0 & 0 \\
\hline du 'black' & 13.16 & 20.83 & 0 & 0 & 0 \\
\hline
\end{tabular}

Table 4 Saturation values per order of derivation for adjectives

\begin{tabular}{|l|l|l|l|l|}
\hline & \multicolumn{1}{|c|}{1 st order } & \multicolumn{1}{|c|}{ 2nd order } & \multicolumn{1}{|c|}{ 3rd order } & \multicolumn{1}{|c|}{ 4th order } \\
\hline Nouns & $19.999 \%$ & $16.001 \%$ & $10 \%$ & 0 \\
\hline Verbs & $17.63 \%$ & $14.2 \%$ & $11.67 \%$ & $13.33 \%$ \\
\hline Adjectives & $27.08 \%$ & $16 \%$ & $10 \%$ & $10 \%$ \\
\hline
\end{tabular}

Table 5 Average saturation values per order of derivation for all three word-classes

\section{Orders of derivation}

Table 6 shows the maximum number of derivational orders for each of the three wordclasses, followed by the average number of orders. Adjectives and verbs have fourth-order derivatives (cf. Table 1), although the numbers are low (one adjectival derivative, four verbal ones), while nouns only have three orders. Verbs have the highest average number of orders, although nouns and adjectives follow close behind. In all three word-classes, a word is likely to have more than one order of derivation.

\begin{tabular}{|l|c|c|}
\hline & Maximum & Average \\
\hline Nouns & 3 & 1.8 \\
\hline Verbs & 4 & 2.1 \\
\hline Adjectives & 4 & 1.6 \\
\hline
\end{tabular}

Table 6 maximum and average number of orders of derivation 


\section{Derivational capacity}

Table 7 shows the maximum and the average derivational capacities for the three wordclasses, calculated using the direct (i.e. first order) derivatives. A basic Welsh noun in our sample has on average seven direct derivatives and the maximum number found is thirteen. Verbs have the highest difference between the average (6.7) and maximum (16 for gwybodlgwybydd- 'know') number of derivatives, which means that there is considerable variation between lexemes.

\begin{tabular}{|l|c|c|}
\hline & Maximum & Average \\
\hline Nouns & 13 & 6.7 \\
\hline Verbs & 16 & 6.5 \\
\hline Adjectives & 10 & \\
\hline
\end{tabular}

Table 7 Average and maximum derivational capacity of the three word-classes

Table 8 shows the average number of derivatives per order of derivation for each word-class. The average Welsh noun in the sample has seven derivatives in the first order, 2.4. in the second order, and 0.1 in the third order. There is no major difference between word-classes in the first order of derivation, but in further orders verbs have more derivatives than nouns or adjectives.

\begin{tabular}{|l|c|c|c|c|}
\hline Word-class & 1st order & 2nd order & 3rd order & 4th order \\
\hline Nouns & 7 & 2.4 & 0.1 & 0 \\
\hline Verbs & 6.7 & 4.4 & 1.4 & 0.4 \\
\hline Adjectives & 6.5 & 1.6 & 0.3 & 0.1 \\
\hline
\end{tabular}

Table 8 Average number of derivatives per order of derivation for all three word-classes

\section{Correlation between semantic categories and orders of derivation}

The most common semantic categories for nouns in the first order of derivation are QUALITY (value 9, i.e. 9 out of 10 nouns have a derivative in this category), ACTION (value 7) and RELATIONAL (value 6). For second order derivatives, ABSTRACTION (value 3) and PRIVATIVE (value 3 ) each occur with three words, and in the third order we only find a single derivative, 
Pre-publication version

For the definitive version, see https://doi.org/10.1515/9783110686630-031

which comes under ACTION.

For verbs, the most common categories in the first order are QUALITY (value 7), ABILITY (value 6) and SINGULATIVE (value 4). In the second order, these are QUALITY and ABSTRACTION (each with value 3). In the third order, QUALITY occurs with two words (value 2), and in the fourth order, ABSTRACTION occurs with two (value 2).

For adjectives, the most common categories in the first order of derivation are STATIVE (value 9), ACTION (value 8) and PROCESS (value 7). In the second order, these are QUALITY (value 4) and STATIVE (value 3). In the third order, only two categories have a value at all (value 1 in each), namely ABSTRACTION and RELATIONAL.

Derivatives of second to fourth orders are few in all three word-classes, and there appear to be no significant correlations between the order of derivation and semantic categories.

\section{Semantic categories with blocking effects}

With the Welsh words used in this study, second order derivation is available for 19 out of the 30 sample words, most commonly for verbs. Only 4 words in total have a third order derivative, while 3 of those also have a fourth order one. No word has fifth order derivatives. Not having a second order derivative is, then, very common, and not having a third or fourth order one is the norm. Because of the paucity of affixation beyond the first order, we cannot demonstrate that any particular semantic category systematically blocks further derivation.

\section{Typical combinations of semantic categories}

There are no combinations of semantic categories that can really be described as typical, due to the general poverty of derivation beyond the first order in Welsh, as discussed above. Some combinations occur in the network of two different lexemes, e.g. PROCESS > PRIVATIVE for both carreg 'stone' and llosg- 'burn'. Only one combination, ACTION > QUALITY, occurs with three lexemes (llosg- 'burn', clodd- 'dig' and $c i$ 'dog'); this is not enough to constitute typicality.

\section{Multiple occurrence of semantic categories}


Pre-publication version

For the definitive version, see https://doi.org/10.1515/9783110686630-031

There are six cases of multiple occurrence of a semantic category in one derivational chain. ABILITY > ABILITY occurs in the network of torr- 'to cut': toradwy 'broken; breakable' > toradwyedd 'breakability'. ACTION > ACTION is also found with llosg- 'to burn', and $c i$ 'dog' has ACTION > QUALITY > ACTION. ABSTRACTION > ABSTRACTION is attested for enw 'name' and gwybod-/gwybydd- 'to know' and ABSTRACTION > QUALITY > ABSTRACTION for gwybodlgwybydd- 'to know'. DIRECTIONAL > ABSTRACTION > QUALITY > ABSTRACTION occurs with tynn- 'to pull'. Finally, we find the chain REFLEXIVE > ABSTRACTION > REFLEXIVE for gwybod-/gwybydd- 'to know': ymwybod 'consciousness, awareness' > ymwybyddiaeth 'consciousness, awareness' > hunanymwybyddiaeth 'self-consciousness, self-awareness'.

\section{Reversibility of semantic categories}

The following pairs of semantic categories can occur in reversed order of derivation (of the type $\mathrm{AB} / \mathrm{BA}$ ) in the network of one basic word: ABSTRACTION-PRIVATIVE (for the lexeme gwybod-/gwybydd- 'to know'), ABSTRACTION-QUALITY ('to know'), ABSTRACTION-REFLEXIVE ('to know'), CAUSATIVE-QUALITY (enw 'name'), PRIVATIVE-QUALITY ('to know'). This means that, for instance, the network of gwybod-/gwybydd- 'to know' includes derivatives with a privative meaning based on a derivative denoting abstraction (e.g. arwybod 'awareness, cognition' > diarwybod 'unexpected, unaware'), and also a derivative with an abstract meaning based on one with a privative meaning (e.g. anwybodus 'ignorant, unknowing' > anwybodusrwydd 'ignorance').

\section{Reasons for structurally poor derivational networks}

Welsh has relatively poor derivational networks compared to many languages in this study. Many of the semantic categories are expressed by means other than derivational affixes. As already stated in the introduction, the categories AGENT, and sometimes also INSTRUMENT, are often expressed with the affixoids -wr and -wraig, from ghw 'man' and gwraig 'woman'.

The category DIMINUTIVE is most commonly expressed by periphrastic means, by modifying a noun with the adjective bach 'small'. The derivational diminutive suffixes - yn, en and -an are not very commonly used, although three nouns in the sample have such diminutives, accepted by native speakers as being possible in spoken usage: asgwrn 'bone' (dimin. esgyrnyn), llygad 'eye' (dimin. llygedyn) and carreg 'stone' (dimin. cerigyn and 
caregan). However, llygedyn is somewhat lexicalised, with most modern attestations having the meaning 'the smallest amount of; ray, glimmer', e.g. llygedyn o obaith 'a glimmer of hope'.

Periphrasis is also the means of expressing semantic categories such as DESIDERATIVE, DIRECTIONAL, DURATIVE, FINITIVE, INCEPTIVE, etc.

HYPERONYMY and HYPONYMY are often expressed by compounding with the adjectival forms $u w c h$ - 'higher-ranking' (comparative of uchel 'high') or is- 'lower-ranking' (comparative of isel 'low'). The adjective prif 'principal, main' can also be used to denote hyperonomy (see Zimmer 2000: 25). New words formed with these adjectives are compounds rather than derivatives, since each adjective also exists as an independent word.

It should be noted that for many of the 30 basic words, there are many derivatives which are attested historically, but which are either no longer in use, or possibly never became productive once they were coined ad hoc. Searching through the main dictionary, Geiriadur Prifysgol Cymru (ed. Thomas et al.), we often find derivatives with only one recorded attestation, and if no further examples could be found in corpora or on Google, such words were not included in the derivational networks.

\section{Conclusions}

The average number of derivational orders for the three word-classes in Welsh varies between 1.6 and $2.1 ; 3$ rd and 4th order derivations are very rare and no lexeme in the sample has 5 th order derivations. Of the three word-classes, verbs have the largest maximum derivational networks in all orders of derivation (see Table 1).

Adjectives have the overall highest saturation value in the first order (27\%, Table 5). In the second order, the saturation values vary between $16 \%$ (nouns and adjectives) and 14\% (verbs), so there is a significant drop between the two orders for adjectives, while nouns and verbs do not change as much between the two orders.

Of the 49 semantic categories used in this study, 26 are available for Welsh lexemes. While some occur commonly for different lexemes (e.g. QUALITY and ACTION, see 'Correlation between the occurrence of individual semantic categories and the order of derivation' above), others are only attested once (e.g. HYPERONYMY, seen in enw 'name' > cyfenw 'surname'). All in all, almost half of the semantic categories are covered by means other than derivational morphology in Welsh, including compounding and periphrasis. 


\section{Acknowledgements}

* I would like to thank Laura Arman and Peredur Webb-Davies, as well as other members of the Welsh Linguistics Seminar in 2017, for providing native-speaker judgements on the derivational networks.

\section{References}

Borsley, Robert D., Maggie Tallerman \& David Willis. 2007. The Syntax of Welsh.

Cambridge Syntax Guides. Cambridge: Cambridge University Press.

Evans, D. Simon. 1964. A Grammar of Middle Welsh. Dublin: Dublin Institute for Advanced Studies.

Griffiths, Bruce \& Dafydd Glyn Jones. 1997. The Welsh Academy English-Welsh

Dictionary/Geiriadur yr Academi. Cardiff: University of Wales Press.

http://geiriaduracademi.org/ (accessed 20/3/2018).

Nurmio, Silva. 2017. Collective nouns in Welsh: a noun category or a plural allomorph? Transactions of the Philological Society 115(1), 58-78.

Russell, Paul. 1989. Agent suffixes in Welsh: native and non-native. Bulletin of the Board of Celtic Studies 36. 30-42.

Russell, Paul. 1990. Celtic word-formation: the velar suffixes. Dublin: Dublin Institute of Advanced Studies.

Russell, Paul, 1995. An introduction to the Celtic languages. London: Longman.

Russell, Paul, 1996. "Verdunkelte Komposita” in Celtic, Studia Celtica 30, 113-125. 
Pre-publication version

For the definitive version, see https://doi.org/10.1515/9783110686630-031

Russell, Paul. 2015a. Verbal nouns in Celtic. In Peter O. Müller, Ingeborg Ohnheiser, Susan Olsen, and Franz Rainer (eds.), Word-Formation: An International Handbook of the Languages of Europe. 5 vols. Berlin, Boston: De Gruyter Mouton. 1230-1241.

Russell, Paul. 2015b. Welsh. In Peter O. Müller, Ingeborg Ohnheiser, Susan Olsen, and Franz Rainer (eds.), Word-Formation: An International Handbook of the Languages of Europe. 5 vols. Berlin, Boston: De Gruyter Mouton. 2769-2781.

Thomas, Peter Wynn. 2006. Gramadeg y Gymraeg [A grammar of Welsh]. 3rd edn. Cardiff: University of Wales Press.

Thomas, R. J., et al. (eds.), 1950-. Geiriadur Prifysgol Cymru/A Dictionary of the Welsh Language, Cardiff: University of Wales Press (2nd edition from 2003-, ed. Gareth, A. Bevan \& P. J. Donovan et al., available online at http://www.geiriadur.ac.uk (accessed 16/12/2017).

Zimmer, Stefan. 2000. Studies in Welsh word-formation. Dublin: Dublin Institute for Advanced Studies. 